\title{
Percepçôes e experiências dos homens sobre o planejamento familiar no sul de Moçambique
}

I ${ }^{1}$ Vânia Manuel Pedro, ${ }^{2}$ Esmeralda Celeste Mariano, ${ }^{3}$ Kristien Roelens,

${ }^{4}$ Nafissa M. R. Bique Osman I

Resumo: O estudo explora as percepções e experiências dos homens sobre o planejamento familiar (PF) em dois contextos do sul de Moçambique: na localidade de Macarretane (província de Gaza) e no bairro da Mafalala (cidade capital, de Maputo). Combinando métodos qualitativos, exploram-se os conhecimentos e práticas dos homens sobre o PF, bem como percebem seu papel (e envolvimento) na saúde sexual reprodutiva e as formas de diálogo e negociação com suas parceiras sobre o PF. O PF foi definido apenas como barreira às gravidezes indesejadas. Os conhecimentos dos homens sobre o PF do ponto de vista biomédico são fracos. Existe a percepção de que os contraceptivos modernos criam efeitos secundários no corpo da mulher, colocando em risco sua capacidade reprodutiva e o prazer sexual. A capacidade ou incapacidade de negociar o uso do PF pelas mulheres é influenciada pelas normas de gênero e pelas masculinidades vigentes. Os homens consideram que o seu papel no PF é de consentir que as parceiras façam planejamento. O diálogo e a articulação em torno do uso dos serviços de PF também são influenciados pelas normas de gênero e padrões de masculinidade.

> Palavras-chave: percepções; experiências; planejamento familiar; Moçambique; homens.

\author{
1 Universidade Eduardo \\ Mondlane, Faculdade de \\ Medicina, Programa Desafio. \\ Maputo, Moçambique \\ (vaniamanuel.pedro@gmail. \\ com). \\ ${ }^{2}$ Universidade Eduardo \\ Mondlane, Faculdade de \\ Letras e Ciências Sociais, \\ Departamento de Arqueologia \\ e Antropologia. Maputo, \\ Moçambique (esmeralda. \\ mariano@uem.mz). \\ ${ }^{3}$ Universidade de Ghent, \\ Bélgica; e Universidade Eduardo \\ Mondlane, Programa Desafio. \\ Maputo, Moçambique (kristien \\ roelens@uzgent.be). \\ ${ }^{4}$ Universidade Eduardo \\ Mondlane, Programa Desafio. \\ Maputo, Moçambique (nafissa. \\ osman@gmail.com).
}


A Conferência Internacional para Desenvolvimento da População (ICPD), realizada no Cairo em 1994, assinalou uma mudança significativa de paradigma no contexto da Saúde Sexual e Reprodutiva (SSR), na medida em que se alterou o foco da população para as pessoas, do macro para o micro e do crescimento e redução da fertilidade para os direitos, necessidades, expectativas e ambições dos indivíduos (COLLUMBIEN; HAWKES, 2000).

Após a ICPD, as pesquisas sobre a saúde e sexualidade do adolescente, violência contra as mulheres, o aborto e os assuntos a ele relacionados, experiências das mulheres sobre as infecções reprodutivas e seu tratamento, emergiram. Porém, no geral, esses estudos estão centralizados em populações femininas. Ainda escasseiam estudos sobre os problemas de saúde reprodutiva na perspectiva dos homens, tal como eles percebem (HARDON et al., 2001).

$\mathrm{O} P F$ pode ajudar na diminuição da mortalidade associada à gravidez, parto e pós-parto. A utilização eficaz da contracepção pode reduzir a mortalidade materna por complicações, pois dá oportunidade às mulheres de adiarem a gravidez, de espaçarem os nascimentos e de reduzirem o número de gravidezes indesejadas que podem terminar num aborto inseguro na maioria das vezes.

O quinto Objetivo de Desenvolvimento do Milênio (ODM) preconiza a melhoria da saúde materna, através da redução da taxa de mortalidade materna em três quartos e alcance do acesso universal à Saúde Reprodutiva. Em Moçambique, o Programa Nacional de Planejamento Familiar tem como meta primordial melhorar as condições de saúde da mulher, porém, 11 mulheres morrem por dia e 3.840 por ano, devido a complicações relacionadas com a gravidez e o parto (MINISTÉRIO DA SAÚDE, 2009).

O sistema de cuidados de saúde em Moçambique é predominantemente suportado pelo setor público e consiste numa rede primária (de 652 postos de saúde e 435 centros de saúde); rede secundária (de 27 hospitais rurais e 8 hospitais distritais); rede terciária (de 5 hospitais gerais e 7 provinciais) e rede quartenária (de 3 hospitais centrais) (MBOANE; BHATTA, 2015).

Apesar de o Programa Nacional de Planejamento Familiar ter iniciado em 1977, somente em 1980 se estabeleceu como um programa efetivo de âmbito nacional, com prestação de serviços aos diferentes níveis da rede de instituições públicas de saúde, com os objetivos de: 
- Melhorar as condições de saúde da mulher, especificamente das mulheres com alto risco reprodutivo que contribuem significativamente para as altas taxas de morbimortalidade materna e perinatal;

- Melhorar a saúde das crianças, promovendo um intervalo de pelo menos dois anos entre um nascimento e o seguinte (MINISTÉRIO DA SAÚDE, 2010).

Atualmente, os serviços de PF continuam a ser majoritariamente públicos e oferecidos de forma gratuita, estando sob a responsabilidade do Serviço Nacional de Saúde (SNS) e encontrando-se integrados ao atendimento materno-infantil (ibidem).

Os serviços de PF não contemplam o sincretismo entre os métodos biomédicos e autóctones/tradicionais. É apenas entendido como PF a contracepção que ocorre no contexto do SNS, sendo este o principal responsável pelo fornecimento de contraceptivos a 77\% das usuárias (MINISTÉRIO DA SAÚDE, 2011). Na Estratégia de Planejamento Familiar e Contracepção 2011-2015 (2020), elaborada pelo Ministério da Saúde (MISAU), todos os métodos de sabedoria popular concerntes à contracepção são definidos como tradicionais nos seguintes termos: "O termo 'tradicional' refere-se a práticas que permitem controlar a fertilidade através da aplicação de métodos comportamentais associados à ovulação, tais como a abstinência, o sexo não penetrativo, coito interrompido, amenorreia da lactação (prolongamento da amamentação) e o método do ritmo (calendário)."

A taxa contraceptiva em Moçambique é de 11,5\% (MINISTÉRIO DA SAÚDE, 2011). De acordo com o Population Reference Bureau (2014), Moçambique possui a terceira taxa contraceptiva mais baixa da África Oriental, depois do Sudão do Sul, com 4\% e da Eritreia, com 8\%. As Ilhas Maurício apresentam a maior taxa contraceptiva da região na ordem dos $76 \%$, seguidas pelas Ilhas Reunião, com $67 \%$, pelo Zimbabwe, com 59\%, pelo Ruanda, com 52\%, pelo Quênia, com $46 \%$, pela Zâmbia, com $41 \%$ e pela Tanzânia, com $34 \%$.

Uma das razóes para que a taxa contraceptiva em Moçambique continue baixa deve-se à oposição dos homens em apoiarem as parceiras no uso dos serviços de PF (MBOANE; BHATTA, 2015). Esses autores mostraram no seu estudo que o poder de decisão do marido ou esposo acerca dos cuidados de saúde teve uma influência negativa na intenção de as mulheres moçambicanas utilizarem contraceptivos. 
Para melhorar o nível de adesão aos serviços de PF e a taxa contraceptiva é preciso antes perceber o que é que os homens sabem sobre a matéria, o que pensam e como é que se comportam perante o assunto, para melhor delinear estratégias de intervenção adequadas aos beneficiários dos programas. Entender as percepções e experiências dos homens sobre o PF implica destrinchar o conceito de masculinidade(s), de gênero e a interseção entre esses dois conceitos e as variáveis classes sociais, raça, etnia e geração.

De acordo com Connell (2000, p. 1), questôes acerca dos homens são inevitáveis, pois gênero é um sistema vivo de interações sociais. O que afeta a posição social de mulheres e raparigas também deve afetar a posição social de homens e rapazes. Grande número de homens reconhece que as suas posições estão sendo desafiadas e o que eles assumiram como garantido precisa ser repensado.

Nesse sentido, utilizamos gênero como categoria analítica que nos permite perceber relações de poder e de desigualdade entre homens e mulheres. Apoiamonos nas definições de gênero de Earle e Letherby (2003), para quem gênero designa, por um lado, as características sociais e culturais prescritas para homens e mulheres, mas por outro, identifica as características socialmente construídas que definem e relacionam homens a mulheres no seio de contextos específicos (ARREGUI, 2004), mas mais do que isso, implica entender gênero como relaçôes de poder, compreendendo por poder a capacidade de levar alguém a fazer algo ou a comportar-se de certo modo, independentemente da sua vontade (WEBER, 1922).

Connell (2000) faz notar que a masculinidade é fruto de uma construção social e que os estudos sobre homens têm como foco os processos sociais de construção da masculinidade, relacionando-os com determinados contextos socioculturais. De acordo com a autora, as masculinidades não existem antes da observância do comportamento social, quer como estados corporais ou personalidades fixas, mas mais do que isso, as masculinidades ganham existência à medida que as pessoas agem. Elas são materializadas todos os dias na conduta assumida na vida organizacional, como padrões da prática social.

Conell \& Messerschmidt (2005) ilustram que a pesquisa social empírica foi uma grande fonte para o avanço dos estudos sobre a(s) masculinidade(s). Esses estudos adicionaram um realismo etnográfico, confirmando a pluralidade de masculinidades e as complexidades da construção de gênero para homens e deu evidências de uma luta ativa pelo domínio implicíto no conceito gramsciano de hegemonia. 
Apesar de poderem existir muitos tipos de masculinidade e coexistirem, há um tipo de masculinidade hegemônica num dado contexto sociocultural. Masculinidade hegemônica pode ser entendida como uma posição cultural de autoridade e liderança, mas não de domínio total. Outras formas de masculinidade persistem em concomitância. Ela não precisa ser a forma mais comum de masculinidade. Ela tende a ser mais visível e pode ser relacionada ao papel do homem. A masculinidade hegemônica não deve ser vista apenas em relação a outras masculinidades, mas também quanto às relações de gênero no geral (CONNELL, 2000). De acordo com Conell \& Messerschmidt (2005), o conceito de masculinidade hegemônica, formulado na década 1990, tem influência significativa no pensamento recente sobre homens, gênero e hierarquia social. Ele foi inicialmente proposto em relatórios de campo sobre certas situaçôes empíricas na Austrália (ibidem).

Nas sociedades tradicionalmente dominadas por homens, não se leva em consideração a necessidade de preservar a saúde da mulher (DE GITA, 2007). A problemática em torno das percepções e experiências dos homens sobre o PF reside no fato de, em algumas sociedades no sul de Moçambique, as mulheres não deterem o poder de decisão sobre os mais diversos assuntos, entre os quais a aderência ou não ao $\mathrm{PF}$, apesar de este oferecer vantagens para a sua saúde e permitir melhor planejar a sua vida.

As relaçôes de gênero no sul de Moçambique também acarretam consequências para a saúde dos homens. De acordo com Macia (2011), no sul de Moçambique a saúde dos homens, por várias razôes, tem merecido pouca atenção (por exemplo: os homens têm problemas de Saúde Sexual e Reprodutiva, incluindo a disfunção sexual). Ainda de acordo com esse autor, as normas prevalecentes de masculinidade no sul de Moçambique impedem que os homens sejam proativos quanto à sua própria saúde, incluindo procurar informação mais correta e fidedigna sobre assuntos da mesma.

Em Moçambique, a estratégia de PF e contracepção lançada pelo MISAU, em 2010, não mostra de forma clara e operacionalizável como é que as necessidades de saúde reprodutiva dos homens serão tidas em conta, apesar de postular a equidade de gênero como um dos seus princípios orientadores. A estratégia em causa igualmente reconhece que o SNS não está preparado para prover serviços de PF aos homens. 
Ainda que o SNS não esteja preparado para prover serviços de PF para os homens, é importante que se saiba de que forma poderá se fazer esse provimento, na medida em que eles têm as suas especificidades e é preciso conhecer as suas crenças, motivações, valores, inquietaçôes e significados que atribuem às suas práticas, a fim de se criar serviços a eles direcionados e melhorar os seus conhecimentos e habilidades em matéria de contracepção, para que estejam engajados em ter comportamentos e atitudes saudáveis para si, parceira e filhos.

Os estudos sobre masculinidade em Moçambique, de um modo geral, têm incidido mais na sua relação com as normas de gênero, HIV/AIDS e violência doméstica (PASSADOR, 2013; MACIA et al., 2011). O estudo de Aboim (2008), apesar de versar sobre as masculinidades, concentrou-se na (re) construção das masculinidades após a aprovação, em 2003, da nova Lei da Família de Moçambique, que postula valores modernistas e igualitários sobre a família e gênero. Poucas pesquisas têm se concentrado no papel que a masculinidade e as normas de gênero jogam na adesão aos serviços de PF. Nesse sentido, consideramos que o nosso trabalho pode constituir uma contribuição nessa área.

Nos estudos acima mencionados e no nosso, é possível identificar que o padrão de masculinidade hegemônica no sul de Moçambique, onde os estudos foram realizados, assenta na ideia de que o homem é o principal provedor e a figura que detém autoridade. Esse modelo de masculinidade continua a exercer forte influência no seu comportamento e atitudes nas mais variadas esferas da vida social.

A nossa abordagem sobre as percepções e experiências dos homens em torno do PF permite ter um ponto de vista sobre o assunto a partir dos próprios homens e auxiliar, desse modo, no desenho de programas de PF e estratégias de intervenção mais consentâneas com a realidade social encontrada.

Este artigo tem por objetivo explorar as percepções e experiências dos homens que têm parceiras em idade reprodutiva (15-49 anos) sobre o Planejamento Familiar (PF) no sul de Moçambique. No sentido de responder ao nosso objetivo, elaboramos a seguinte pergunta de pesquisa: "Quais são as percepções e experiências dos homens em Macarretane e em Mafalala acerca do Planejamento Familiar?”. Importa citar que neste artigo apresentamos as percepçōes e experiências mais salientes referidas pelos nossos interlocutores. 


\section{Contexto de estudo}

O estudo foi realizado em dois contextos, nomeadamente: na localidade de Macarretane e no bairro da Mafalala. A localidade de Macarretane localiza-se no distrito de Chòkwé, província de Gaza a oeste da região do sul de Moçambique (CHÒKWÉ, 2010). O distrito tem 182.967 habitantes, que compreendem 80.376 homens e 102.591 mulheres. Conta com 37.753 agregados familiares e uma densidade populacional aproximada de $72 \mathrm{hab} / \mathrm{km}^{2}$ (CHOKWWÉ, 2010).

O principal grupo etnolinguístico do distrito é o Changana. A linhagem das famílias de Chòkwé é patrilinear, sistema no qual a tomada de decisão é feita pelos homens. As religiōes professadas no distrito são: católica, metodista, anglicana, islâmica, presbiteriana e outras seitas protestantes. As mulheres são responsáveis pela agricultura e atividades domésticas, ao passo que os homens (especialmente os jovens), pela pastagem. Além desta atividade, um número considerável de homens emigra para a África do Sul à procura de emprego nas minas, farmas, serviços de construção, entre outros (ibidem).

O bairro da Mafalala localiza-se no distrito municipal KaMaxakeni, na capital de Moçambique, a cidade de Maputo. A população total do bairro é de 223.936 habitantes, sendo 10.204 homens e 10.774 mulheres, e existem no bairro da Mafalala 4.266 agregados familiares (CONSELHO MUNICIPAL DA CIDADE DE MAPUTO, 2010).

Mafalala é produto de correntes migratórias da Ilha de Moçambique, como uma das consequências da transferência da capital da Ilha de Moçambique para Lourenço Marques, atual Maputo. O bairro registra um crescimento desordenado e, como resultado, saneamento precário e deficiente disposição de certos serviços e bens públicos (CRUZ E SILVA, 2003). Não foge à regra da estrutura ocupacional dos grandes polos urbanos de Moçambique. Para além de servirem às instituições públicas e privadas da zona de cimento, os residentes dedicam-se a micronegócios no bairro, oscilando entre o comércio informal, carpintaria e costura (ibidem).

Realizamos o estudo na localidade de Macarretane, no distrito de Chòkwé, porque, de acordo com Tvedten et al. (2010, p. 20), existe no distrito uma forte tradição patriarcal com um sistema patrilinear de descendência e uma supremacia econômica masculina através do controle do gado e da migração laboral, assim 
como uma grande incidência de HIV/AIDS que parece atingir mulheres de forma particularmente forte.

Outrossim, Chòkwé localiza-se na província de Gaza, que apresenta a maior taxa de soroprevalência de HIV, estimada em $25,1 \%$, maior que a média nacional, na ordem dos 11,5\% (INSIDA, 2009). Igualmente, o distrito de Chòkwé constitui um dos corredores rodoviários de Maputo, por onde passam vários bens, serviços e pessoas, o que é propício para a ocorrência de Múltiplos Parceiros Concorrentes.

Trabalhamos em Mafalala porque o bairro é considerado multicultural, convivendo no mesmo local estrangeiros e pessoas oriundas de diversos cantos de Moçambique, sobretudo da região norte, que é marcadamente islâmico, contrariamente ao sul, assinaladamente cristão. Por essas razões, julgamos encontrar em Mafalala diversas percepções e experiências sobre o PF. De acordo com o INSIDA (2009), a taxa de soroprevalência na cidade de Maputo, onde se situa Mafalala, é de 16,8\%, e a taxa contraceptiva na cidade de Maputo (capital do país), de 35\% (IDS, 2011).

\section{Métodos}

Os dados foram colhidos durante dois meses, usando a perspectiva qualitativa. A pesquisa qualitativa responde a questóes muito particulares. Ela se ocupa, nas Ciências Sociais, com um nível de realidade que não pode ou não deveria ser quantificado. Ou seja, ela trabalha com o universo dos significados, dos motivos, das aspiraçôes, das crenças, dos valores e das atitudes (MINAYO, 2009).

Trabalhar questões referentes ao PF significa fazer uma incursão no campo da subjetividade, da sexualidade e do relacionamento entre homens e mulheres, e envolve significados e valores construídos socialmente, mas que nem sempre são verbalizados pelos usuários e pelos profissionais de saúde (ARAÚJO, 2004, p. 31).

Utilizamos uma combinação de quatro técnicas: discussões em grupos focais, entrevistas individuais semiestruturadas, conversas informais e observação participante. Cada um destes métodos serviu a objetivos específicos e possibilitou o processo de triangulação. Os métodos foram desenhados de modo a serem complementares.

Os informantes-chave incluíram homens, mulheres, autoridades comunitárias, autoridades do setor de saúde e alguns profissionais de saúde que trabalham na 
área do PF. Foram realizadas 24 entrevistas semiestruturadas, sendo $12 \mathrm{com}$

homens (5 em Mafalala e 7 em Macarretane) e 12 com mulheres (6 em Mafalala e 6 em Macarretane). Apesar de o estudo ter como grupo primário homens com parceiras em idade reprodutiva, incluímos mulheres como informantes, porque, por um lado, o conceito de género é relacional e homens e mulheres são responsáveis pelo PF; e por outro, os programas de PF no nosso país, e não só, são centralizados nas mulheres.

Cada participante foi entrevistado, em média, duas vezes, e alguns deles participaram de alguns dos grupos focais, o que possibilitou fazer uma análise dos seus discursos individuais e coletivos. Nosso estudo utilizou uma combinação de dois tipos de amostragem não probabilística, nomeadamente: a amostragem por conveniência e a snowball (bola de neve), tendo como horizonte a saturação da amostra.

Antes da realização das entrevistas, foi explicado aos participantes quais eram os objetivos do estudo, solicitou-se sua colaboração e foram negociadas as condições para seu envolvimento, tomando em conta os vários aspectos éticos, entre os quais a gravação das entrevistas semiestruturadas. Estas foram gravadas com o prévio consentimento dos participantes, para auxiliar os investigadores a registrar maior informação possível, sem perder a atenção a outros aspectos durante a condução das entrevistas, que duraram, em média, trinta minutos.

Conscientes da dificuldade de se discutir assuntos de âmbito privado, os pesquisadores optaram por segmentar as interaçôes em campo de acordo com o sexo. A pesquisadora principal trabalhou com mulheres e o seu colega de sexo masculino, com homens, de forma a garantir maior empatia na interação sobre temáticas intímas da vida dos participantes. Ao longo do texto, utilizamos pseudônimos para resguardar o anonimato e confidencialidade dos participantes do estudo.

Foram realizados seis grupos focais, sendo quatro com homens (2 em Mafalala e 2 em Macarretane) e dois com mulheres (1 em Mafalala e 1 em Macarretane). Nos dois grupos focais com homens em Macarretane, participaram seis em cada. Sete mulheres participaram no grupo focal em Macarretane. Seis homens participaram no primeiro grupo focal em Mafalala e seis no segundo grupo focal em Mafalala. No grupo focal com mulheres em Mafalala participaram mulheres. Os grupos focais duraram uma hora. 
As entrevistas e os grupos focais foram majoritariamente realizados em espaços em que se podia garantir a privacidade dos informantes, e foram feitos após a leitura e a gravação do consentimento informado.

\section{Resultados}

\section{Conhecimento, experiências e uso do planejamento familiar}

Os participantes do estudo deram diferentes respostas sobre o seu conhecimento acerca do PF. Alguns definiram o PF de forma incompleta, realçando apenas a prevenção da gravidez indesejada através da pílula, injeção ou preservativo, não mencionando o papel destes contraceptivos no espaçamento entre os nascimentos dos filhos, tal como a narrativa abaixo sugere:

Já ouvi dizer que tem que levar-se a esposa para o hospital e solicitar o serviço de PF. Dizem que colocam Dispositivo Intra-Uterino (DIU) e quando precisar conceber, tira-se. Quando já não se quer ter mais filhos, deixa-se assim (Maússe, 42 anos, em união de fato poligâmica com duas mulheres, Macarretane).

Outros participantes disseram desconhecer o PF e outros relataram que o $\mathrm{PF}$ visa à prevenção de doenças, porque a pessoa pode ir à Unidade Sanitária com o seu parceiro para evitar doenças. Importa dizer que homens assim como mulheres estão presentes nestas três categorias de respostas.

No que concerne às vantagens do $\mathrm{PF}$, a maioria dos participantes comentou que este serviço apresenta apenas vantagens, porque permite suprir as necessidades na educação e sustento dos filhos, uma vez que o nível de vida está se tornando insustentável. Apenas um participante considerou o PF desvantajoso, explicando:

Se a minha esposa faz planejamento enquanto eu ainda quero filhos acho que não é bom, só se tivermos combinado que já não queremos filhos (João, 24 anos, casado, Mafalala).

Conhecer o conceito de PF sob a ótica biomédico é um bom ponto de partida para que os usuários possam apropriar-se dos serviços de PF de forma informada, livre e consciente (ONYANGO et al., 2010). Por um lado, concordamos que o conhecimento adequado é pré-requisito para o uso dos serviços de PF, mas por outro, o conhecimento sobre o PF não pode ser visto como condição sine qua non para o seu uso.

A obtenção de um novo conhecimento e sua consequente aplicação não é tão linear, porque às vezes os indivíduos adquirem um novo conhecimento, mas a sua história de vida tem grande influência sobre o seu comportamento. A esse 
respeito, Gazzinelli et al. (2005, p. 201) referem o seguinte: "desconsidera-se que no processo educativo lida-se com estórias de vida, um conjunto de estórias de vida, crenças, valores, a própria subjetividade do sujeito que requer soluçôes sustentadas socioculturalmente."

Quanto às vantagens e desvantagens do $\mathrm{PF}$, a motivação por parte de João para considerar o PF desvantajoso também foi documentado no estudo de Marshall (1977 apud RINGHEIN, 1993), que afirma que o uso de um certo método contraceptivo é influenciado pelo desejo do indivíduo de prevenir ou evitar a gravidez e também do estágio da sua vida reprodutiva, o que significa que pessoas que ainda não tiveram filhos ou que já os tenham, mas queiram ter mais, tenderão a não fazer o PF ou a utilizar contraceptivos de curto e médio prazo.

Quanto ao conhecimento dos contraceptivos, a pílula, a injeção e o preservativo são os contraceptivos mais conhecidos tanto pelos homens como pelas mulheres. De um modo geral, as mulheres conhecem mais os métodos contraceptivos cujo uso e administração dependem delas, como a pílula e a injeção, e o mesmo sucede com os homens (ver tabela 1).

Tabela 1. Contraceptivos mais referidos pelos participantes das entrevistas semiestruturadas e grupos focais

\begin{tabular}{|l|l|l|l|l|l|l|l|l|l|}
\hline & \multicolumn{7}{|c|}{ Métodos contraceptivos referidos pelos participantes do estudo } \\
\hline Sexo & Pílula & Injeçáo & DIU & Preservativo & Implante & Calendário & Vasectomia & $\begin{array}{l}\text { Coito } \\
\text { interrompido }\end{array}$ & Laqueaçáo \\
\hline Masculino & 37 & 37 & 5 & 37 & 0 & 1 & 1 & 4 & 0 \\
\hline Feminino & 25 & 25 & 15 & 20 & 0 & 3 & 0 & 0 & 2 \\
\hline
\end{tabular}

No tocante ao uso dos serviços de PF, foi possível identificar quatro grupos de respostas, nomeadamente: 1) Homens que referiram que as suas parceiras fazem o PF com recurso à pílula ou injeção; 2) Homens que utilizam o preservativo como contraceptivo; 3) Mulheres que referiram não fazer o PF; 4) Mulheres que fazem o PF com recurso a pílula ou injeção.

No geral, quanto aos contraceptivos, a pílula é o mais utilizado, seguido do preservativo. Em Macarretane, a pílula é o mais usado e em Mafalala, é o preservativo. A razão para o maior uso da pílula em Macarretane tem a ver com o fato de, por um lado, o PF ser encarado como responsabilidade das mulheres, 
pois elas é que ficam grávidas, mas por outro, porque elas é que têm maior contato com as questões contraceptivas. Ao passo que em Mafalala, por um lado, os homens tendem a ter maior consciência da importância do PF, e por outro, porque vêm o preservativo como um método de barreira que evita as Infecções de transmissão sexual e a gravidez indesejada (ver tabela 2).

Tabela 2. Contraceptivos utilizados pelos participantes do estudo das entrevistas semiestruturadas e dos grupos focais

\begin{tabular}{|l|l|l|l|l|l|l|}
\hline \multicolumn{4}{|c|}{ Macarretane } & \multicolumn{5}{c|}{ Mafalala } & \\
\hline Contraceptivos & Homens & Mulheres & Contraceptivos & Homens & Mulheres & Total \\
\hline Pílula & 8 & 6 & Pílula & 3 & 7 & 24 \\
\hline Injeção & 1 & 2 & Injeção & 2 & 1 & 6 \\
\hline Laqueação & 0 & 1 & Laqueação & 0 & 0 & 1 \\
\hline Preservativo & 3 & 0 & Preservativo & 12 & 0 & 21 \\
\hline DIU & 0 & 0 & DIU & 1 & 0 & 1 \\
\hline Ku mbonha & 1 & 0 & Ku mbonha & 0 & 0 & 1 \\
\hline Calendário & 1 & 0 & Calendário & 0 & 1 & 2 \\
\hline Nenhum & 1 & 1 & Nenhum & 1 & 3 & 6 \\
\hline
\end{tabular}

Para além dos contraceptivos modernos, foram igualmente mencionados alguns métodos "tradicionais". ${ }^{2}$

Pode se tomar comprimidos, mas as outras mulheres usam métodos tradicionais como a cinza. Acordam de madrugada misturam cinza e tomam, outras usam ervas como o capim, mas não sabemos como se faz, são várias formas. Outras tomam café para não engravidar (Grupo focal 1, homens, Macarretane).

O processo de inserção de certas substâncias nos genitais femininos para evitar a gravidez, bem como a ingestão de certas ervas, foi documentado no trabalho de Bagnol e Mariano (2011), que identificaram e descreveram um conjunto de práticas vaginais e ingestão de ervas utilizadas pelas mulheres em Tete com a finalidade de garantir o prazer durante o ato sexual, induzir o aborto e lavar e purificar os genitais. Igualmente, o processo de inserção de certas substâncias nos genitais femininos para evitar a gravidez, bem como a ingestão de certas ervas, foi documentado no trabalho de Wambui et al. (2009), no Quênia. 
Importa aqui salientar que o IDS de 2011 refere que a taxa de uso de contraceptivos tradicionais é insignificante, na ordem de 0,3\%. Apesar de não termos quantificado o grau de uso dos contraceptivos tradicionais, notamos, através do nosso estudo, que tanto em Macarretane, como em Mafalala, estes são conhecidos e utilizados por algumas mulheres.

Quanto à experiência com os contraceptivos, alguns dos participantes relataram que certos contraceptivos modernos, como a pílula e a injeção, criam efeitos adversos no corpo das mulheres, como, por exemplo: aumento de peso corpóreo, irregularidades no ciclo menstrual, alteração no prazer sexual, e atuam como estimulantes para a infidelidade, na medida em que são vistos como fomentadores da vontade frequente de ter relaçôes sexuais. Sobre os métodos tradicionais, as mulheres afirmaram não sentir efeitos negativos. Tais percepções sobre os efeitos adversos dos contraceptivos modernos foram recorrentes em Macarretane e não em Mafalala.

Gostamos do planejamento, mas há coisas que acontecem que as vezes criam problemas às nossas mulheres. Usam comprimidos e injeçôes depois já não menstruam. As vezes engordam e a vagina delas fica cheia de água ("xitale a mati”) e não há mais prazer durante o sexo (Grupo focal 1, homens, Macarretane).

Quando alguns dos homens vão trabalhar para África do Sul, as mulheres ficam a fazer das suas e isso é preocupante. Nós apoiaríamos o PF, se as mulheres fizessem na mesma altura que os seus maridos estão em casa, mas as mulheres são muito espertas e aplicam injeção de 6 meses, depois dormem com outros homens e o marido não descobre. Antes o marido descobria através de uma gravidez, mas agora já não é possível (Grupo focal 2, homens, Macarretane).

Algumas das participantes do estudo narraram as suas experiências com os contraceptivos modernos. No geral, a maioria foi alternando no uso de diferentes contraceptivos, por causa dos desconfortos que alguns deles criavam. O exemplo de Joana é elucidativo a esse respeito, porque ela oscilou entre muitos métodos, até que o marido e ela sentiram a necessidade de optar por uma laqueação.

No começo fui buscar comprimidos, mas não me caíram bem. Quando tomava ficava enjoada e parecia estar grávida, enquanto não estava. Se não me criassem enjoo, faziam com que quando tivesse relações sexuais, aparecesse hemorragia. Depois utilizei injeção por quase durante 5 anos e não menstruava.

Fui ao hospital e disse que queria deixar de usar injeção, porque não me sentia bem com o meu organismo. Deram-me uns comprimidinhos para provocar o período. (...) Depois fiquei grávida e perdi o bebé. 
Recomecei o uso da injeção porque vi que poderia ficar grávida novamente. Quando recomecei os pés ficaram inchados e já não me caía bem, e deixei. Fiquei dois anos sem ficar grávida, mas no terceiro ano fiquei grávida do bebé que tenho agora. Também experimentei o aparelho [DIU], mas com medo porque dizem que as vezes pode deslocar-se dentro do organismo e criar complicações no útero. Agora é que pedi para fazerem-me a laqueação, mas não sei se fizeram (Joana, 34 anos, em união de fato, Macarretane).

\section{Papel do homem no Planeamento Familiar}

No geral, os homens e mulheres que participaram no estudo consideram que o papel do homem no PF é permitir que a sua parceira dirija-se à Unidade Sanitária e faça uso dos contraceptivos. Alguns homens entendem que o PF é unicamente da responsabilidade da mulher, porque ela é quem fica grávida e os contraceptivos são a ela distribuídos. Outros participantes, que ambos têm o seu papel no tocante ao PF, mas tem que ser o homem a permitir que seja feito o PF. Igualmente, esse grupo de participantes, quando solicitado a elaborar mais sobre o papel do homem e da mulher no PF, acabou dizendo que cabia ao homem consentir que a parceira utilize os métodos contraceptivos. Um dos participantes referiu que sua esposa deveria ir buscar informação sobre o PF e contraceptivos e informá-lo, para que ele pudesse tomar a sua decisão com conhecimento de causa.

No que tange ao papel do homem no PF, os resultados do nosso estudo mostram que eles consideram, por um lado, que as questôes de PF são de domínio feminino, mas que, por outro, o seu papel é de decidir se as mulheres fazem ou não o PF. Este ponto de vista dos homens pode ser explicado a partir da relação que Loforte (2007) estabelece entre gênero e saúde, nota-se de que forma os papéis de gênero condicionam a participação dos homens na Saúde Sexual e Reprodutiva. Loforte (2003) comenta que as dimensōes culturais e simbólicas regulam os comportamentos dos indivíduos, particularmente no exercício da sexualidade.

Em Macarretane, o modelo de masculinidade vigente é ancorado num sistema linhageiro e de descendência patrilinear. Fazendo uma relação entre masculinidade e gênero, associada aos resultados do nosso estudo, constatamos que, em Macarretane, o fato de os homens serem detentores do poder de decisão enfraquece a aderência das mulheres aos serviços de PF.

Em Mafalala, apesar de o modelo hegemônico de masculinidade ser similar ao de Macarretane, notamos a existência de uma pluralidade de masculinidades, pois 
Mafalala é um aglomerado de pessoas oriundas de diversos lugares do país, com religiōes e ocupações diversificadas e situa-se na cidade cosmopolita de Maputo.

Comparativamente a Macarretane, em Mafalala, os sujeitos da nossa pesquisa olham para o PF como algo vantajoso e há maior espaço para negociação entre os parceiros sobre os diversos aspetos da vida, incluindo o PF. Tal abertura ao PF por parte da maioria dos nossos sujeitos de pesquisa em Mafalala tem como razão, por um lado, a combinação entre gênero, classe, raça, etnia, geração, que permite fazer uma leitura mais abrangente das masculinidades. Por outro, devese ao fato de as masculinidades serem permanentemente reconstruídas, tanto por mudanças políticas e econômicas, como pela ação individual, alterando o equilíbrio entre os modelos hegemônico e não hegemônico (ABOIM, 2008).

$\mathrm{Na}$ esfera reprodutiva é o homem quem decide quando ter filhos, quantos ter, quando fazer PF e quando parar de fazer. No contexto da procriação, homens e mulheres têm tarefas diferenciadas, fruto da construção dos papéis de gênero. Nos contextos do estudo, predomina a imagem de que o corpo da mulher é apenas a casa do feto e que a criança se desenvolve a partir do esperma do homem (LOFORTE, 2000). Sendo assim, ele é quem tem o poder de decidir quando ter filhos e quantos ter.

Alguns estudos sobre o envolvimento masculino no PF e na Saúde Sexual e Reprodutiva documentam que, quando os homens são envolvidos nas questôes reprodutivas, os resultados dos programas de saúde que operam nessa área têm sido melhores, na medida em que os homens é que tomam as decisões, daí a importância de eles estarem cientes sobre o seu papel nas questóes contraceptivas (BECKER, 1996).

\section{Formas de diálogo e negociação entre o casal sobre o uso do PF}

As formas de diálogo e negociação entre o casal sobre o PF são permeadas pelas relaçôes de gênero e influencidadas pelo tipo de masculinidades existentes em um dado contexto sociocultural. O diálogo entre o casal/parceiros e a negociação sobre a contracepção são aspectos importantes, porque o formato de PF vigente tende a focalizar a sua atenção sobre as mulheres, enquanto elas não são as detentoras do poder de decisão.

Em Macarretane, apesar de prevalecer uma masculinidade hegemônica ancorada num sistema linhageiro e de descendência patrilinear, registramos casos 
1328 de homens que têm outra abordagem sobre a importância de dialogar e negociar com as parceiras quanto à necessidade de utilizar o PF.

A ideia de fazer o PF partiu do meu marido por ver que já temos muitos filhos. Mesmo quando parei de fazer PF porque me fazia mal, ele se zangou comigo (Joana, 34 anos, em união de fato, Macarretane).

Quando o meu marido está cá sempre falamos do PF. Ele é que começa e diz que temos que ir ao PF para podermos criar a criança (Fátima, 24 anos, em união de fato, Macarretane).

Por ser professor, o marido de Joana tem outra percepção sobre o PF. Este exemplo realça, uma vez mais, a importância de não olhar apenas para uma única variável na leitura das masculinidades e sua relação com o PF.

As formas de diálogo e negociação entre os casais sobre o PF são influenciadas por alguns fatores, como, por exemplo: diferenças entre os casais, crenças religiosas, nível de escolaridade, capacidade de se autossustentar e até pela influência que as famílias exercem na vida do casal (DE GITA, 2007).

$\mathrm{O}$ fato de algumas mulheres serem as primeiras a abordar seus parceiros sobre o PF é explicado por serem elas a receber as informaçōes sobre o PF em primeira mão, porque frequentam mais as Unidades Sanitárias do que os homens e porque em algum momento gostariam de parar de conceber. Contudo, ainda que sejam as primeiras a falar sobre seus desejos reprodutivos aos seus parceiros, a sua capacidade de negociar o uso do PF precisa ser reforçada.

A tese de Ratcliffe et al. (2001) de que comunicação e negociação não fazem parte de certos contextos culturais africanos é discutível, porque nem sempre o contexto sociocultural determina a ação dos indivíduos. Os resultados do nosso estudo mostram que há casais que conversam sobre o $\mathrm{PF}$, embora não seja frequente.

O fato de alguns casais serem uma exceção à regra e dialogarem sobre as questôes contraceptivas em contextos marcadamente patrilineares tem a ver com a diversidade de elementos que influenciam na negociação, que mencionamos previamente.

\section{Conclusão}

Os homens e mulheres neste estudo têm conhecimento limitado sobre o Planejamento Familiar sob o ponto de vista biomédico. As mulheres, de um modo geral, apresentam maior conhecimento sobre o assunto, porque são o sujeito primário dos programas de PF. 
Durante o estudo, notamos que existem diferentes modelos de masculinidade,

mas a masculinidade hegemônica em Macarretane e em Mafalala assenta numa ideologia e sistema linhageiro patrilinear. Segundo esta, os homens é que tomam as decisões sobre os mais diversos aspectos da vida da família, incluindo sexualidade e procriação. A forma como são construídas e reconstruídas as masculinidades tem uma implicação direca no modo como os homens percepcionam e experimentam o PF.

Relativamente ao papel do homem no PF, os resultados do estudo sugerem que eles concebem o seu papel no PF como o de conceder permissão para que as suas parceiras o façam.

A partir dos resultados do nosso estudo, propomos o seguinte:

a) A capacitação de homens como educadores de pares no domínio do Planejamento Familiar para que possam sensibilizar os demais sobre a importância do PF, uma vez que geralmente pessoas do mesmo sexo têm mais empatia e partilham alguns interesses em comum;

b) Introdução de temáticas de gênero, SSR e PF nos currículos a partir do nível básico de ensino, de maneira a conscientizar os homens ainda em tenra idade sobre a importância do seu envolvimento nas questôes reprodutivas;

c) Criação de Unidades Sanitárias específicas ou de condições de atendimento exclusivo para o aconselhamento e saúde dos homens, pois, à semelhança das mulheres, eles também têm suas dúvidas, anseios, expectativas e receios no que concerne à saúde no geral, e à SSR, em especial. ${ }^{3}$

\section{Referências}

ABOIM, S. Masculinidades na encruzilhada, hegemonia, dominação e hibridismo em Maputo. Análise social. Lisboa, v. XLIII (2), p. 273-295, 2008.

ARAÚJO, F. Açōes de Educação em Saúde no Planeamento Familiar nas Unidades de Saúde da Família do Município de Campina Grande-PB. 2004. Curso de (especialização em saúde da família para profissionais do programa de saúde de família) - Campina Grande-PB, Paraíba.

ARREGUI, M. Manual de capacitação em equidade de género, 2004. Disponível em: <http//: www.americalatinagenera.org $>$. Acesso em: 23 fev. 11.

BAGNOL, B.; MARIANO, E. Género, sexualidade e práticas vaginais. Maputo: DAA/ FLECS/UEM, 2011.

BECKER, S. Couples and reproductive health: A review of couples studies. Stud Fam Plann, v. 27, n. 6, p. 291-306, 1996. 
COLLUMBIEN, M.; HAWKES, S. Missing men's messages: does the reproductive health approach respond to men's sexual health needs?. Culture, Health \& Sexuality, v. 2, n. 2, p. 135-150, 2000.

CONNELL, R. W. Understanding men: gender sociology and the new international research on masculinities. Kansas, 2000.

CONNELL, R. W.; MESSERSCHMIDT, J. W. Hegemonic masculinity: rethinking the concept. Gender \& Society, v. 19, no. 6, 2005.

CONSELHO MUNICIPAL DA CIDADE DE MAPUTO. Perfil estatístico do Município de Maputo 2007-2008. Maputo, 2010.

CHÒKWÉ (Distrito). Plano Estratégico de Desenvolvimento do Chòkwé. 2010.

CRUZ E SILVA, T. As redes de solidariedade como intervenientes na resolução de litígios: o caso da Mafalala. In: SANTOS, B.; TRINDADE, J. (Orgs.). Conflito e transformação social: uma paisagem das justiças em Moçambique, V. II. Porto: Edições Afrontamento, 2003, p. 427-450.

DE GITA, G. Spousal communication and Family Planning behavior in Northern Cape, South Africa. 2007. Master (thesis in statistics) - Department of Statistics, University of Cape Town, 2007.

EARLE, S.; LETHERBY, G. Introducing Gender, Identity and Reproduction. In: EARLE, S.; LETHERBY, G. (Eds.) . Gender, identity and reproduction: social perspective. New York: Palgrave Macmillan, 2003.

GAZZINELLI, M. et al. Educação em Saúde: conhecimentos, representações sociais e experiências da doença. Cadernos de Saúde Pública, v. 21, n. 1, p. 200-206, 2005.

HARDON, A.; STREEFLAND, P.; TAN, M. Applied Health Research Manual: anthropology of health and health care. 3. ed. Amsterdam: Het Spinhuis Publishers, 2001.

INQUÉRITO NACIONAL DE PREVALÊNCIA, RISCOS COMPORTAMENTAIS E INFORMAÇÕES SOBRE O HIV E SIDA (INSIDA). Ministério da Saúde de Moçambique. Maputo, 2009.

LOFORTE, A. Género e poder entre os Tsonga. Maputo: Promédia, 2000.

LOFORTE, A. Práticas culturais em relação à sexualidade e representaçôes sobre saúde e doença. Maputo: CEP/FLECS/UEM, 2003.

LOFORTE, A. Inequidades e valores em saúde reprodutiva: vulnerabilidades das mulheres num contexto de feminização do SIDA. In: DEGREGORI, M. (Coord.). Mulher, SIDA, e o acesso à saúde na África Subsahariana, sob perspectiva das Ciências Sociais. Barcelona: Médicus Mundi Catalunya, 2007. 
MACIA, M. Comportamento sexual masculino e práticas preventivas no contexto duma epidemia generalizada do HIVI SIDA: um estudo de caso duma área urbana e rural, sul de Moçambique. In: ENCONTRO DE PARTILHA DE PESQUISAS EM PREVENÇÃO E COMUNICAÇÃO SOBRE O HIV EM MOÇAMBIQUE, 2011, Maputo.

MINAYO, M. C. O desafio da pesquisa social. In: MINAYO, M. C. (Org.). Pesquisa Social: teoria, método, criatividade. Petrópolis: Vozes, 2009, p. 9-29.

MINISTÉRIO DA SAÚDE. Parceria nacional para promoção da saúde materna, neonatal e infantil. Maputo, 2009.

. Estratégia de Planeamento Familiar e Contracepção 2010-2015. Maputo, 2010. . Inquérito Demográfico e de Saúde. Maputo, 2011.

MBOANE, R.; BHATTA, M. Influence of Husbands'shealthcare decision making role on a woman's intention to use contraceptives among mozambican women. Reprod Health, v. 12, n. 36, 2015.

ONYANGO, M.; OWOKO, S.; OGUTTU, M. Factors that influence male involvement in Sexual and Reproductive Health in Western Kenya: a qualitative study. African Journal of Reproductive Health, v. 14, n. 4, p. 33, 2010.

PASSADOR, L. H. Masculinidades e construção social da violência. Boletim outras vozes. Maputo, 2013, p. 1-6.

POPULATION REFERERENCE BUREAU. World population data sheet, 2014. Disponível em: < http://www.prb.org/pdf14/2014-world-population-data-sheet_eng.pdf>. Acesso em: 18 set. 2015.

RATCLIFFE, A. A. et al. Editorial: The ignored role of men in fertility awareness and regulation in Africa. African Journal of Reproductive Health, n. 13-15, 2001.

RINGHEIN, K. Factors that determine prevalence of contraceptive methods for men. Stud. Fam. Plan, v. 24, p. 87-99, 1993.

TVEDTEN, I.; PAULO, M.; TUOMINEN, M. Não fica bem que uma mulher seja chefe quando há homens: género e pobreza no sul de Moçambique. Bergen: Chr. Michelsen Institute (CMI Report R 2007:7 (Port)).

WAMBUI, T.; EK, A-C; ALEHAGEN, S. Perceptions of family planning among lowincome men in western Kenya. International nursing review, v. 56, p. 340-345, 2009.

WEBER, M. Três tipos puros de poder legitimo, 1922. 1-12 p. Disponível em: < http://www. lusosofia.net/textos/weber_3_tipos_poder_morao.pdf>. Acesso em: 2 ago. 2016.

\section{Notas}

${ }^{1}$ Ku mbonha é um termo em língua Tsonga (falada no sul de Moçambique), que significa tapar (tradução nossa). 
${ }^{2}$ Métodos "tradicionais", de acordo com o IDS de 1997, incluem chás, ervas e sortilégios. Neste trabalho, consideramos métodos contraceptivos "tradicionais" aqueles que são de conhecimento de certa "comunidade" para evitar as gravidezes indesejadas, através da ingestão ou inserção de ervas no seu corpo.

${ }^{3}$ V. M. Pedro participou do desenho do projeto de investigação; realização do trabalho de campo; interpretação e análise de dados, redação e defesa da dissertação de Mestrado em Saúde Pública, elaboração e submissão do artigo para a publicação. E. C. Mariano participou da orientação do projeto de investigação e da dissertação de Mestrado em Saúde Pública; contribuição na concepção e revisão completa do artigo. K. Roelens contribuiu no desenho do estudo; na interpretação dos dados e na revisão do artigo para a publicação. N. M. R. B. Osman contribuiu no desenho do estudo; na interpretação dos dados e na revisão do artigo para a publicação. 


\section{Abstract}

Perceptions and experiences of men on family planning in southern Mozambique

The study explores the perceptions and experiences of men about family planning (FP) in two contexts of southern Mozambique: in the locality of Macarretane (Gaza province) and in the Mafalala neighborhood (capital city of Maputo). Combining qualitative methods, men's knowledge and practices about FP are explored, as well as perceiving their role (and involvement) in reproductive sexual health and the forms of dialogue and negotiation with their partners about FP. PF was only defined as a barrier to unwanted pregnancies. Men's knowledge about FP from a biomedical point of view is weak. There is a perception that modern contraceptives create side effects on a woman's body, putting her reproductive capacity and sexual pleasure at risk. The capacity or inability to negotiate the use of FP by women is influenced by gender norms and masculinities in force. Men feel that their role in FP is to allow their partners to plan. Dialogue and articulation around the use of FP services are also influenced by gender norms and patterns of masculinity.

Keywords: perceptions; experiences; family planning; Mozambique; men. 